\title{
What is a Chiropodist?
}

\author{
VALERIE LAL* \\ Leprosy Service, Northern Province, Sierra Leone
}

In order to become a State Registered Chiropodist in the United Kingdom it is now necessary to have undergone a 3-year full-time course of training. Some chiropodists have been admitted to the Register without this training, but their training and/or experience had to have taken place prior to 1963 and they had to satisfy the Chiropodists' Board of their competence, usually by means of a practical and oral test.

In Britain the subjects studied during the 3-year recognized course of training are: the basic sciences, anatomy, physiology, elementary pathology and bacteriology, surgery and medicine in relation to disorders of the lower limb, dermatology, regional surgery, podology, (study of the foot in health and disease), therapeutics, practical chiropody, appliance making, and footwear.

Other countries of fering similar training and qualifications are New Zealand and Australia. France has a 2-year training period, to which a 3rd optional year is expected to be added shortly. The USA has a 4year training scheme leading to a doctorate of surgical chiropody, or podiatry as it is known in the United States.

Many countries have chiropodial societies, but their members receive very little, or no, formal training. In Germany a well-known company which manufactures various foot appliances also offers a 6-week training scheme in chiropody which is available in several countries. Of course very little medical knowledge is obtained in this time, especially as the course is concerned mainly with sales promotion!

\section{The Chiropodists' Rôle in Leprosy}

This includes the following:

(a) RECOGNITION AND TREATMENT OF MINOR INJURIES BEFORE THEY BECOME ULCERS

Most important are the recognition of the pre-ulcer state and subsequent advice, and also supervision to ensure that the patient has complete rest.

Fungus infections, wounds, "jiggers", heel cracks, blisters, and interdigital fissuring are all conditions that may be found in leprosy patients, and these should be treated before they become infected and lead to formation of an ulcer. Such minor lesions on the anaesthetic foot may easily provide entry for bacteria, and if undetected and untreated will "track down" to the deeper tissues.

(b) SPECIALIZED AND INDIVIDUAL TREATMENT OF ULCERS

Mass treatment of plantar ulcers in leprosaria tends to give inadequate results.

* Member of the Chiropodial Society, State Registered Chiropodist. 
In my opinion, based on experience, regular soaking (especially daily soaking) of ulcers deters healing. Soggy wounds do not heal.

The in-patient probably needs to wash his feet when he first attends the chiropodist. After this the foot should be kept dry until healing has occurred. Out-patients generally have to wash their feet at every visit, although if the ulcer has been well dressed on the previous visit and kept dry this may not be necessary. Feet without ulcers should be soaked daily and a little oil applied to aid water retention, and help defective sweat glands.

Recognition of the type of ulcer presented and its effect on underlying tissues is important, as is an assessment of the patient's general disabilities and deformities, and how these in turn affect body-weight distribution. His general health must be taken into consideration, as well as the condition of local tissues immediately surrounding the ulcer and in the lower limbs. If the blood supply to the extremities is good and no infection is present, then quick and good healing can be expected. Poor quality skin with loss of elasticity will need a longer time for healing, as will also previously scarred and deformed feet.

Correct trimming of an ulcer is extremely important in promoting healing in the minimum amount of time. This not only requires the removal of dead and fibrous tissue surrounding the ulcer, but also cutting the callus right down so that it blends into the healthy skin around it. Any other callus on the sole of the foot should be trimmed to leave the plantar surface smooth and even. A certain degree of suppleness may also be obtained in the skin of some feet when trimming is correctly done.

Heel fissures can sometimes be completely cut away, as they are often found to be only "callus deep", but if they are not trimmed they will usually become deeper and eventually open the epidermis. Flaps of dead epidermis, perhaps resulting from a superficial scratch, should be cut away as they provide a lodging place for dirt and bacteria. In unshod races a certain amount of callus formation is functional, so that drastic reduction of callus is to be avoided, especially in the case of out-patients. Patients presenting with osteomyelitis or any other deep-seated infection are referred to the doctor for systemic treatment. Bony sequestra are removed and one of the new enzyme drugs is preferred for local application. We have had very good results with these drugs.

The correct use of medicaments speeds the healing process. Generally speaking, dry ulcers situated in hard anhidrotic skin will respond well to a cream-based medicament, whereas a soggy ulcer will respond more quickly to a powder-based drug. Ulcers should be measured when first seen, and thereafter at each subsequent visit. If little or no progress has been made, then the medicament being used should be changed, and any other suspected underlying cause investigated.

\section{(c) AFTER-CARE AND HEALTH EDUCATION}

When an ulcer has healed the covering skin is usually fairly weak and thin, so that the patient may still require protective dressings in addition to his special sandals. Incidentally, daily soaking at this stage may also re-open the wound.

After being discharged the patient should be able to visit the chiropodist occasionally for checking of his feet, for advice, and for any trimming of the callus that may be necessary. Frequently a hard core of callus forms in the centre of an old plantar ulcer scar. This may fall out of its own accord, but usually it gets pushed deeper into the foot and acts like a stone, penetrating deep into the tissues 
and causing the ulcer to reopen. This callus can be easily removed and a softening agent such as a cream containing vitamins A and D may be applied to improve the quality of the skin.

Health education is given to the patients throughout their treatment and thereafter. They are helped to understand the nature of their disease and its effects. In this way we hope to get their co-operation. They are advised on how to care for their own feet at home in their villages, and made to realize that the responsibility is now mainly theirs.

\section{(d) P.O.P. AND THE KARIGIRI BOOT}

The application of plaster-of-Parıs casts, back-slabs, splints, and the Karigiri boot are well within the capabilities of the chiropodist.

\section{(e) SHOEMAKING}

During their training chiropodists learn to make various foot appliances and simple footwear from different materials. Although the training in this field and the skill and experience acquired cannot be compared to that of an orthopaedic shoemaker, the type of sandal suitable for leprosy patients i.e. those made of microcellular rubber or of Plastazote, is within our capabilities. Many chiropodists, especially the men, enjoy this aspect of the work and seek to further their skills and knowledge after training. With the current shortage of shoemakers perhaps a chiropodist might be considered for this work.

\section{(f) SUPERVISION OF ATTENDANTS AND TRAINING}

A chiropodist employed in a leprosarium will have more time than the doctor for training attendants in, e.g., ulcer care and all the subsidiary education needed to bring about an understanding of the treatment. Furthermore, attendants will work alongside the chiropodist and be encouraged in their work by seeing the results achieved by giving individual treatment to each patient. Too many attendants lose interest in ulcer care simply because they have been told to use the same course of treatment for every patient, a practice which results in a "hit or miss" affair.

\section{(g) ADMINISTRATION}

Correct record keeping and terminology as applied to foot-care is an important part of ascertaining results, reviewing treatment, and conducting surveys.

\section{Acknowledgement}

The authors wish to thank the Society of Chiropodists, London, for their suggestions and information given in preparing this paper. 